\title{
Implementation of Evidence-Based Cervical Ripening Protocol: Outcomes and Next Steps
}

\author{
Arthurine Zakama, MD ${ }^{1}$ (1) Nasim C. Sobhani, MD ${ }^{1}$ (1) Robyn Lamar, MD ${ }^{1}$ \\ Melissa G. Rosenstein, MD, MAS ${ }^{1}$ \\ 1 Department of Obstetrics, Gynecology and Reproductive Sciences, \\ University of California, San Francisco, California \\ Address for correspondence Arthurine Zakama, MD, Department of \\ Obstetrics, Gynecology, and Reproductive Sciences, University of \\ California, 550 16th Street, 7th Floor OBGYN, Mailstop 0132, San \\ Am J Perinatol Rep 2020;10:e408-e412. \\ Francisco, CA 94143 (e-mail: Arthurine.Zakama@ucsf.edu).
}

\begin{abstract}
Keywords

- induction of labor

- cervical ripening

- misoprostol

- Foley

- quality improvement
\end{abstract}

Objective A prominent randomized controlled trial demonstrated that low-dose misoprostol with the concurrent cervical Foley shortened the median time to delivery when compared with either method alone. Our study aims to address implementation of this protocol and evaluate its impact on time to delivery.

Study Design This was a retrospective before-and-after study of nulliparous women who delivered nonanomalous, term, singletons at the University of California San Francisco (UCSF) in two separate 2-year periods before and after changes in UCSF's cervical ripening protocol. The primary outcome was time from first misoprostol dose to delivery.

Results A total of 1,496 women met inclusion criteria, with 698 in the preimplementation group and 798 in the postimplementation group. There were no statistically significant differences in time to delivery ( 29 vs. 30 hours, $p=0.69$ ), rate of cesarean delivery ( 30 vs. $26 \%, p=0.09$ ), or cesarean delivery for fetal indications ( 11 vs. $8 \%$, $p=0.15$ ) between the groups.

Conclusion Implementing evidence-based low-dose misoprostol with the concurrent cervical Foley did not change the time to delivery, time to vaginal-delivery, or likelihood of vaginal delivery in our population. This may be due to differences in labor management practices and incomplete fidelity to the protocol. Real-world effectiveness of these interventions will vary and should be considered when choosing an induction method.

Induction of labor is performed in more than $20 \%$ of all pregnancies in the United States. ${ }^{1}$ In the setting of an unfavorable cervix, labor induction is more successful when the cervix is ripened with pharmacological methods (e.g., administration of misoprostol, a synthetic prostaglandin) and/or through mechanical methods (e.g., placement of the cervical Foley). ${ }^{2}$ Misoprostol alters collagen breakdown, rearranges collagen fibers, and increases intracellular calcium to promote cervical softening and myometrial contractions. ${ }^{3,4}$ Mechanical methods appear to have two mechanisms of action: exerting pressure on the internal cervical os promotes both mechanical dilation and

received

May 15, 2020

accepted after revision

September 24, 2020
DOI https://doi.org/

10.1055/s-0040-1721443. ISSN 2157-6998. release of endogenous prostaglandins from the adjacent decidua (Ferguson's reflex). ${ }^{3-7}$

Prior studies have shown that as single agents, the cervical Foley and misoprostol are both effective methods of cervical ripening; however, it is not clear whether one is superior to the other. ${ }^{1,8,9}$ Sequential use of oral misoprostol and the cervical Foley does not conclusively appear to improve time to delivery or vaginal delivery rates in comparison to simply using oral misoprostol alone. ${ }^{7,10,11}$ However, the simultaneous use of oral misoprostol and the cervical Foley has consistently been demonstrated to shorten time to delivery
Copyright $\odot 2020$ by Thieme Medical Publishers, Inc., 333 Seventh Avenue, 18th Floor, New York, NY 10001, USA Tel: $+1(212)$ 760-0888.
License terms

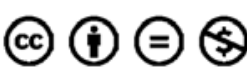


and decrease the risk of failed induction of labor (IOL) in comparison to misoprostol alone. The best example of this is the FOR MOMI trial, a large randomized controlled trial, that investigated these methods as single agents and also in dual use in a four-arm study design. ${ }^{8}$ They compared cervical ripening prior to induction with the cervical Foley alone, misoprostol alone, cervical Foley and vaginal misoprostol, or cervical Foley and oxytocin. The FOR MOMI trial demonstrated that simultaneous use of the cervical Foley and low-dose vaginal misoprostol resulted in a shorter median time to delivery ( $\sim 4$ hours) when compared with either method alone, with no change in mode of delivery or harms to mother or neonate. ${ }^{8}$ These encouraging results prompted many providers to adopt dual agent ripening for IOL. However, most of the data on dual-agent cervical ripening are randomized controlled trials that reflect study efficacy rather than effectiveness. This study aims to address effectiveness in the real world, namely, how implementation of an evidencebased protocol impacted the time to delivery in two historical cohorts pre- and postimplementation of low-dose misoprostol with the concurrent cervical Foley.

\section{Methods}

This was a retrospective before-and-after study of all nulliparous women with term ( $\geq 37$ weeks) singleton pregnancies who underwent a scheduled IOL at the University of California San Francisco (UCSF) from May 2015 to April 2017 and from June 2017 to May 2019. Those with preterm delivery of $<37$ weeks, multifetal gestation, nonvertex fetal presentation, multiparity, prior cesarean delivery, rupture of membranes prior to initiation of IOL, and major fetal anomalies were excluded. In May 2017, the term IOL cervical ripening protocol was changed from misoprostol 50 to $100 \mu \mathrm{g}$ PO every 4 hours with subsequent placement of the cervical Foley once cervical dilation was 1 to $2 \mathrm{~cm}$ (the preimplementation protocol, based on a 2005 prospective IOL trial ${ }^{12}$ ) to misoprostol $25 \mu \mathrm{g}$ PO every 2 hours with simultaneous placement of the cervical Foley filled to $60 \mathrm{~mL}$ (the postimplementation protocol, inspired in large part by the results of the FOR MOMI trial). ${ }^{2}$ The decision to use $25-\mu \mathrm{g}$ oral misoprostol administered every 2 hours (rather than $25-\mu$ g vaginal misoprostol administered every 3 hours, as per the original FOR MOMI protocol) was based on several lines of evidence. Pharmacokinetic data indicate that oral absorption of misoprostol is highly reliable, with minimal variability between patients, compared with vaginal absorption. ${ }^{13,14}$ However, the half-life is much shorter, thus requiring more frequent administration to maintain serum levels. ${ }^{13,14}$ The American College of Obstetricians and Gynecologists (ACOG) provides minimal guidance surrounding the best dosing schedule for misoprostol administration. ${ }^{1}$ However, the World Health Organization (WHO), ${ }^{15}$ International Federation of Gynecology and Obstetrics (FIGO), ${ }^{16}$ and the Royal College of Obstetricians and Gynaecologists (RCOG), ${ }^{17}$ all recommend low dose but frequently administrated misoprostol, based on systematic reviews showing this strategy to be both effective and superior in terms of safety.
For all deliveries at UCSF, details regarding maternal demographics, labor characteristics, and pregnancy outcomes are collected at the time of delivery by the managing clinicians and stored within the UCSF Perinatal Database. Chart review is performed by trained abstractors to ensure complete and accurate information, while monthly review of the database is performed by physicians for quality assurance. We utilized the UCSF Perinatal Database to obtain information regarding maternal demographics (age, race, body mass index [with obesity defined as body mass index $\left.\geq 30 \mathrm{~kg} / \mathrm{m}^{2}\right]$, and parity), details of antepartum and intrapartum course (pregnancyrelated hypertension, chronic hypertension, gestational diabetes, preexisting diabetes, maternal cardiac disease, fetal growth restriction, placental abruption, gestational age at delivery, and mode of delivery) and neonatal characteristics (birthweight, Apgar's scores, and neonatal intensive care unit [NICU] admission).

The primary outcome was time from first misoprostol dose to delivery. Secondary outcomes included overall cesarean delivery rate, cesarean delivery for fetal indications, cumulative misoprostol dose, number of misoprostol administrations, need for oxytocin augmentation, time from oxytocin initiation to delivery, postpartum hemorrhage, chorioamnionitis, low Apgar's score (defined as 5-minute Apgar's score $<7$ ), and NICU admission.

The Kruskal-Wallis test was used to compare median values for nonparametric continuous variables, and Fisher's exact and Chi-squared tests were used to compare proportions for categorical variables. Statistical analyses were performed using STATA v13.0 (StataCorp., College Station, TX). This study was approved by the UCSF Committee on Human Research (study number 19-28095).

\section{Results}

During the study period, a total of 1,496 women met criteria for inclusion, with 698 women in the preimplementation group and 798 in the postimplementation group. There were no statistically significant differences in maternal demographics between the two groups (-Table 1). There was a higher incidence of pregnancy-related hypertension in the preimplementation group compared with the postimplementation group (36 vs. $28 \%, p<0.001$ ); there were no differences in other pregnancy complications or in gestational age at delivery between the two groups.

There was no difference in the primary outcome of time to delivery between the two groups (median of 29 hours for the preimplementation group vs. 30 hours in the postimplementation group, $p=0.68$; - Table 2). The preimplementation group had a significantly higher cumulative misoprostol dose than the postimplementation group ( $150 \mathrm{vs.} 100 \mu \mathrm{g}, p<0.001$ ), while the postimplementation group had significantly more misoprostol administrations ( 4 vs. 2 doses, $p<0.001$ ). A smaller proportion of the preimplementation group required oxytocin augmentation when compared with the postimplementation group ( 81 vs. $88 \%, p=0.001$; - Table 2 ).

There was no statistical difference in cesarean deliveries overall or cesarean deliveries for fetal indication 
Table 1 Maternal demographics and characteristics among nulliparous patients undergoing induction of labor before (preimplementation) and after (postimplementation) the implementation of an evidence-based protocol for cervical ripening

\begin{tabular}{|c|c|c|c|}
\hline Demographics & Preimplementation $(n=698)$ & Postimplementation $(n=798)$ & $p$-Value \\
\hline Maternal age (y) & $33(30-37)$ & $34(31-37)$ & 0.210 \\
\hline \multicolumn{4}{|l|}{ Race } \\
\hline Caucasian & $354(51 \%)$ & $431(54 \%)$ & 0.757 \\
\hline African American & $33(5 \%)$ & $31(4 \%)$ & \\
\hline Hispanic & $63(9 \%)$ & $67(8 \%)$ & \\
\hline Asian & $161(23 \%)$ & $182(23 \%)$ & \\
\hline Other & $78(11 \%)$ & $80(10 \%)$ & \\
\hline Unknown & $9(1 \%)$ & $7(1 \%)$ & \\
\hline Obese & 97 (14\%) & $95(12 \%)$ & 0.250 \\
\hline Chronic hypertension & $49(7 \%)$ & $49(6 \%)$ & 0.493 \\
\hline Pregnancy-induced hypertension & $256(37 \%)$ & $225(28 \%)$ & $<0.001$ \\
\hline Preexisting diabetes & $11(2 \%)$ & $14(2 \%)$ & 0.788 \\
\hline Gestational diabetes & $185(27 \%)$ & $205(26 \%)$ & 0.720 \\
\hline Fetal growth restriction & $28(3 \%)$ & $27(3 \%)$ & 0.567 \\
\hline Placental abruption & $11(2 \%)$ & $16(2 \%)$ & 0.534 \\
\hline Gestational age at delivery & $39.9(38.7-41.1)$ & $39.9(39.0-41.0)$ & 0.882 \\
\hline
\end{tabular}

Note: Continuous variables with nonparametric distribution reported as median (interquartile range).

(preimplementation of $30 \%$ and postimplementation of $26 \%$ [ $p=0.086]$ for any indication; 8 vs. $11 \%$ [ $p=0.145]$ for fetal indication). Multivariate logistic regression to control for potential confounders (maternal age, preexisting diabetes mellitus, gestational diabetes mellitus, chronic hypertension, and pregnancy-related hypertensive disease) failed to find a statistically significant difference in cesarean delivery (adjusted odds ratio $[\mathrm{aOR}]=0.80,95 \%$ confidence interval $[\mathrm{CI}]: 0.63-1.00$ ) or cesar- ean delivery for fetal indication ( $\mathrm{aOR}=0.74,95 \% \mathrm{CI}$ : $0.52-1.05$ ) between the two groups.

The postimplementation group had a significantly higher postpartum hemorrhage rate than the preimplementation group (15 vs. $11 \%, p=0.013$ ); however, there was no statistically significant difference in the rate of postpartum blood transfusion between the two groups (6 vs. 6\%, $p=0.83)$. There was no difference in the rate of low Apgar's

Table 2 Pregnancy outcomes among nulliparous patients undergoing induction of labor before (preimplementation) and after (postimplementation) the implementation of an evidence-based protocol for cervical ripening

\begin{tabular}{|c|c|c|c|}
\hline Demographics & Preimplementation $(n=698)$ & Postimplementation $(n=798)$ & $p$-Value \\
\hline Time from misoprostol start to delivery (h) & $29.1(20.5-41.7)$ & $29.9(20.1-40.5)$ & 0.689 \\
\hline Cumulative misoprostol dose $(\mu \mathrm{g})$ & $150(50-250)$ & $100(50-150)$ & 0.0001 \\
\hline Total number of misoprostol administrations & $2(1-3)$ & $4(2-6)$ & 0.0001 \\
\hline Required oxytocin for augmentation & $568(81 \%)$ & $700(88 \%)$ & 0.001 \\
\hline Time from Pitocin start to delivery $(h)^{a}$ & $16(9.27-22.3)$ & $15(9.70-21.78)$ & 0.817 \\
\hline Cesarean delivery for any indication & $208(30 \%)$ & $206(26 \%)$ & 0.086 \\
\hline Cesarean delivery for fetal indication & $74(11 \%)$ & $67(8 \%)$ & 0.145 \\
\hline Postpartum hemorrhage & $74(11 \%)$ & $119(15 \%)$ & 0.013 \\
\hline Blood transfusion & $41(6 \%)$ & $49(6 \%)$ & 0.829 \\
\hline Chorioamnionitis & $70(10 \%)$ & $94(12 \%)$ & 0.280 \\
\hline Low Apgar's score & $29(4 \%)$ & $50(6 \%)$ & 0.067 \\
\hline NICU admission & $117(17 \%)$ & $76(10 \%)$ & $<0.001$ \\
\hline
\end{tabular}

Abbreviation: NICU, neonatal intensive care unit.

Note: Continuous variables with nonparametric distribution reported as median (interquartile range).

$\mathrm{a}_{n}=568$ for preimplementation group and $n=700$ for postimplementation group. 
scores between the two groups, but there was as a significantly higher rate of NICU admission in the preimplementation group compared with the postimplementation group (17 vs. $10 \%, p<0.001 ;$-Table 2 ).

\section{Discussion}

We found that implementation of an evidence-based concurrent dual agent cervical ripening protocol did not change the median time to delivery or likelihood of vaginal delivery.

Our study expands on the FOR MOMI trial by examining the real-world effects of clinically implementing a protocol of lowdose misoprostol with the concurrent cervical Foley placement. ${ }^{8}$ Unlike the FOR MOMI trial, we did not find a decrease in the median time to delivery with the use of this protocol. Importantly, the median time to delivery in the FOR MOMI trial for the misoprostol with the concurrent cervical Foley group was 13 hours, whereas the median time to delivery in the post implementation group in our study was 30 hours. This discrepancy may be due numerous factors. First, the FOR MOMI trial included both multiparous and nulliparous patients, whereas our study included only nulliparous patients, who have longer induction to delivery times. ${ }^{3,11}$ Second, the cesarean rate for nulliparous woman in the FOR MOMI trial receiving dual-agent was $44 \%$, compared with $26 \%$ in our population. Our lower cesarean rate likely reflects differences in the institutional management of labor and may be due to fewer cesareans for failed induction. Lastly, the variation in route of misoprostol administration (vaginal in FOR MOMI, oral in the present study) may have also contributed to the differences in time to delivery. A recent meta-analysis demonstrated that among all prostaglandins, low-dose ( $<50 \mu \mathrm{g})$ oral misoprostol had the lowest probability of cesarean delivery over time, whereas vaginal misoprostol had the highest probability of achieving a vaginal delivery within 24 hours. ${ }^{18,19}$ This finding aligns with our report of low cesarean delivery rates in the postimplementation (low-dose oral misoprostol) group but longer time to delivery than the FOR MOMI trial, which used the vaginal route.

This study also demonstrated that the postimplementation group had a significantly higher rate of postpartum hemorrhage, which is likely due to the implementation of quantitative blood loss (QBL) measurement during the postimplementation period, rather than a true increase in blood loss at delivery. QBL measurements are more accurate than estimated blood loss (EBL) measurements, which tend to underestimate hemorrhage. ${ }^{20}$ This is supported by the stable rate of transfusions across the time periods.

We also found that the postimplementation group had significantly fewer NICU admissions, a result that is congruent with multiple studies that used similar doses of misoprostol in combination with the cervical Foley. ${ }^{21,22} \mathrm{~A}$ recent meta-analysis of eleven randomized controlled trials found that the combination of misoprostol and the cervical Foley was associated with a reduced risk of NICU admission (relative risk $[\mathrm{RR}]=0.75,95 \% \mathrm{CI}: 0.58-0.97, p=0.03$ ) compared with either method alone. ${ }^{21}$ To our knowledge, there were no other significant changes in NICU admission criteria to explain this finding.

\section{Strengths and Limitations}

The major strength of this study is the evaluation of the implementation of an evidence-based cervical ripening method into real-world practice, with a sample size six times larger than the original FOR MOMI trial, which included 123 women in the misoprostol plus the cervical Foley group. Furthermore, our institutional cesarean delivery rate is much lower, likely reflecting different practice patterns and strategies of labor management. Institutions may need to compare their cesarean delivery rates to those reported in randomized controlled trials of induction methods to determine whether those data will be generalizable to their own populations.

The major limitation of this study is its retrospective nature, which relies on historical cohorts and is limited to what has previously been documented in the electronic medical record. Of note, the indication for NICU admission was not included in the data analysis. Furthermore, the comparison included changes made in dosing of oral misoprostol and in timing of the cervical Foley placement, which limits our ability to determine which changes contributed to the differences we found. Additionally, while the low-dose misoprostol with the concurrent cervical Foley protocol aimed to have the simultaneous cervical Foley and misoprostol, many women still received sequential methods if providers felt that the cervical Foley placement would be difficult; we do not have clear data on the frequency of this occurrence.

\section{Conclusion}

Based on this study and the existing literature, no method of cervical ripening is clearly superior to the others outside of the context of a randomized controlled trial; even then, the differences between the methods are the modest at the best ( $\sim 2-4$ hours). As such, we recommend that undergoing cervical ripening for IOL be counseled in a shared decision-making model. This counseling should include the beneficial evidence of dual agent cervical ripening over individual methods, as well as the differences in timing and frequency of misoprostol administration, timing of the cervical Foley placement, and the impacts on time to delivery and cesarean delivery. Shared decision making in maternity care can decrease decisional conflict, increase satisfaction with the delivery experience, generate more positive feelings toward the newborn, and decrease depressive symptoms. ${ }^{23,24}$

In conclusion, implementing an evidence-based protocol of low-dose misoprostol with the concurrent cervical Foley was not associated with a change in median time to delivery or vaginal delivery rates. While randomized controlled trial data are useful for calculating efficacy of induction methods, real-world effectiveness of these interventions will vary based on local and institutional practice and should be considered when choosing an induction method.

Conflict of Interest

None declared. 


\section{References}

1 ACOG Committee on Practice Bulletins - Obstetrics. 107: induction of labor. Obstet Gynecol 2009;114(2 Pt 1):386-397

2 Alfirevic Z, Kelly AJ, Dowswell T. Intravenous oxytocin alone for cervical ripening and induction of labour. Cochrane Database Syst Rev 2009;(04):CD003246

3 Kehl S, Ehard A, Berlit S, Spaich S, Sütterlin M, Siemer J. Combination of misoprostol and mechanical dilation for induction of labour: a randomized controlled trial. Eur J Obstet Gynecol Reprod Biol 2011;159(02):315-319

4 Hill JB, Thigpen BD, Bofill JA, Magann E, Moore LE, Martin JN Jr. A randomized clinical trial comparing vaginal misoprostol versus cervical Foley plus oral misoprostol for cervical ripening and labor induction. Am J Perinatol 2009;26(01):33-38

5 Jozwiak M, Bloemenkamp KW, Kelly AJ, Mol BWJ, Irion O, Boulvain M. Mechanical methods for induction of labour. Cochrane Database Syst Rev 2012;(03):CD001233

6 Atad J, Hallak M, Auslender R, Porat-Packer T, Zarfati D, Abramovici $\mathrm{H}$. A randomized comparison of prostaglandin E2, oxytocin, and the double-balloon device in inducing labor. Obstet Gynecol 1996;87(02):223-227

7 Kehl S, Ziegler J, Schleussner E, et al. Sequential use of doubleballoon catheter and oral misoprostol versus oral misoprostol alone for induction of labour at term (CRBplus trial): a multicentre, openlabel randomised controlled trial. BJOG 2015;122(01):129-136

8 Levine LD, Downes KL, Elovitz MA, Parry S, Sammel MD, Srinivas SK. Mechanical and pharmacologic methods of labor induction: a randomized controlled trial. Obstet Gynecol 2016;128(06): 1357-1364

9 Ten Eikelder MLG, Oude Rengerink K, Jozwiak M, et al. Induction of labour at term with oral misoprostol versus a Foley catheter (PROBAAT-II): a multicentre randomised controlled non-inferiority trial. Lancet 2016;387(10028):1619-1628

10 Kehl S, Böhm L, Weiss C, et al. Timing of sequential use of doubleballoon catheter and oral misoprostol for induction of labor. J Obstet Gynaecol Res 2016;42(11):1495-1501

11 Kehl S, Weiss C, Dammer U, et al. Double-balloon catheter and sequential oral misoprostol versus oral misoprostol alone for induction of labour at term: a retrospective cohort study. Eur J Obstet Gynecol Reprod Biol 2016;204:78-82

12 Colón I, Clawson K, Hunter K, Druzin ML, Taslimi MM. Prospective randomized clinical trial of inpatient cervical ripening with stepwise oral misoprostol vs vaginal misoprostol. Am J Obstet Gynecol 2005;192(03):747-752
13 Tang OS, Gemzell-Danielsson K, Ho PC. Misoprostol: pharmacokinetic profiles, effects on the uterus and side-effects. Int J Gynaecol Obstet 2007;99(Suppl 2):S160-S167

14 Kundodyiwa TW, Alfirevic Z, Weeks AD. Low-dose oral misoprostol for induction of labor: a systematic review. Obstet Gynecol 2009;113(2 Pt 1):374-383

15 World Health Organization. WHO Recommendations for Induction of Labour. Accessed October 17, 2020 at: https://apps.who.int/iris/ bitstream/handle/10665/44531/9789241501156_eng.pdf;jsessionid $=8$ C559C1CDF51DE26A9A0CF84CB4D7092 sequence $=1$

16 International Federation of Gynecology and Obstetrics. The global voice for women's health. Accessed April 9, 2020 at: https://www. figo.org/sites/default/files/uploads/project-publications/Miso/ FIGO_Dosage_ChartEN_0.pdf

17 National Collaborating Centre for Women's and Children's Health Commissioned by the National Institute for Health and Clinical Excellence. Induction of labour. Accessed October 17, 2020 at: https://www.nice.org.uk/guidance/cg70

18 Alfirevic Z, Keeney E, Dowswell T, et al. Labour induction with prostaglandins: a systematic review and network meta-analysis. BMJ 2015;350:h217-h217

19 Ten Eikelder MLG, Mast K, van der Velden A, Bloemenkamp KWM, Mol BW. Induction of labor using a foley catheter or misoprostol: a systematic review and meta-analysis. Obstet Gynecol Surv 2016;71(10):620-630

20 Al Kadri HMF, Al Anazi BK, Tamim HM. Visual estimation versus gravimetric measurement of postpartum blood loss: a prospective cohort study. Arch Gynecol Obstet 2011;283(06):1207-1213

21 Ornat L, Alonso-Ventura V, Bueno-Notivol J, Chedraui P, PérezLópez FR. Misoprostol combined with cervical single or double balloon catheters versus misoprostol alone for labor induction of singleton pregnancies: a meta-analysis of randomized trials. J Matern Neonatal Med 2019;33(20):3453-3468

22 Husain S, Husain S, Izhar R. Oral misoprostol alone versus oral misoprostol and Foley's catheter for induction of labor: A randomized controlled trial. J Obstet Gynaecol Res 2017;43(08): 1270-1277

23 Attanasio LB, Kozhimannil KB, Kjerulff KH. Factors influencing women's perceptions of shared decision making during labor and delivery: Results from a large-scale cohort study of first childbirth. Patient Educ Couns 2018;101(06):1130-1136

24 Klassa PJ, Dendrinos S, Penn A, Radke J. Shared decision making: through the patient's eyes. J Perinat Neonatal Nurs 2016;30(03): 228-232 